\title{
An ADAMTS13 mutation that causes hereditary thrombotic thrombocytopenic purpura: a case report and literature review
}

\author{
Pengzhu Li, Jie Jiang, Qiong Xi and Zuocheng Yang*
}

\begin{abstract}
Background: Mutations in the ADAMTS13 gene can lead to an ADAMTS13 enzyme deficiency, which is related to Upshaw-Schulman syndrome (USS). USS is a common type of thrombotic thrombocytopenic purpura (TTP). Here we present a very rare case of TTP caused by 2 mutations in the ADAMTS13 gene. Besides, we reviewed and summarized previous pathogenic ADAMTS13 gene mutations associated with the TTP.

Case presentation: A 10-year-old female was admitted to the Third Xiangya Hospital of Central South University after experiencing discontinuous thrombocytopenia for 8 years, abnormal renal function for more than 2 years, cough for more than 10 days, and weakness of the left limb for 3 days. Gene sequencing shows the patient's ADAMTS13 gene contains compound heterozygous nucleotide variations: c.1335delC (p. Phe445LeufsTer52) is a frameshift variation inherited from her father and c.2130C > G (p. Cys710Trp) is a missense variation inherited from her mother. The final diagnosis was USS.
\end{abstract}

Conclusions: Our study reports a very rare genetic TTP case caused by two compound heterozygous variants in the ADAMTS13 gene. The effect of these two mutations on the secretion of ADAMTS13 requires further in vitro experiments to confirm.

Keywords: Gene mutation, Thrombotic thrombocytopenic purpura, ADAMTS13, Upshaw-Schulman syndrome

\section{Background}

Thrombotic thrombocytopenic purpura (TTP) is a rare but critical clinical disease; its pathogenesis is mainly due to the lack of the von Willebrand factor-cleaving enzyme (ADAMTS13), and thus the von Willebrand factor (vWF) molecule is not cleaved in the plasma, and a large number of platelets aggregate and conducts widespread microvascular thrombosis. The disease is approximately $2-3$ times more common in women than in men, particularly among young and middle-aged people. According to the NCBI ClinVar database, greater than 260 ADAMTS13 mutation sites have been identified, of which 29 of 24

*Correspondence: yang_zcr@126.com

Department of Pediatrics, The Third Xiangya Hospital, Central South

University, Changsha 410013, Hunan, People's Republic of China patients had been determined to be pathogenic mutations, as shown in Table 1. Herein, we report a unique TTP case in which new compound heterozygous nucleotide variations were confirmed by gene sequencing. To further understand the characteristics of this disease, we reviewed previously reported pathogenic cases.

\section{Case presentation}

Our patient was a 10-year-old female, who presented with discontinuous thrombocytopenia of 8 years, abnormal renal function of more than 2 years, cough of more than 10 days, and weakness of the left limb of 3 days. She was delivered at full term by caesarean section and weighed $3 \mathrm{~kg}$, without asphyxia. Her parents were nonrelated and her mother was healthy during pregnancy. She was fed formula milk after birth. No family history of 
Table 1 Pathogenic mutations in the ADAMTS13 gene in patients with Upshaw-Schulman syndrome

\begin{tabular}{|c|c|c|c|c|c|c|c|}
\hline Patient no & Ethnicity & $\begin{array}{l}\text { Site of } \\
\text { mutation } \\
\text { (exon no.) }\end{array}$ & Nucleotide change & $\begin{array}{l}\text { Amino acid } \\
\text { change }\end{array}$ & $\begin{array}{l}\text { Mutation } \\
\text { type }\end{array}$ & Clinical manifestation & References \\
\hline \multirow[t]{2}{*}{1} & \multirow[t]{2}{*}{ Turkish } & exon 3 & c.291_319del29 & p. Glu98Profs & Frameshift & \multirow[t]{2}{*}{ Chronic recurrent TTP } & \multirow[t]{2}{*}{ [16] } \\
\hline & & exon 29 & c.4143dupA & $\begin{array}{l}\text { p. Glu- } \\
\text { 1382Argfs }\end{array}$ & Frameshift & & \\
\hline 2 & Iranian & exon 23 & $\begin{array}{l}\text { c.2931_2936delGTG } \\
\text { CCC }\end{array}$ & $\begin{array}{l}\text { p. Cys977- } \\
\text { Arg979delin- } \\
\text { sTrp }\end{array}$ & Frameshift & Not available & [16] \\
\hline 3 & American & exon 17 & c. $2074 C>T$ & p. Arg692Cys & Missense & $\begin{array}{l}\text { Had a chronic relapsing course, } \\
\text { responded to plasma infusion }\end{array}$ & [17] \\
\hline 4 & American & exon 3 & c. $286 C>\mathrm{G}$ & p. His96Asp & Missense & $\begin{array}{l}\text { Had a chronic relapsing course, } \\
\text { responded to plasma infusion }\end{array}$ & [17] \\
\hline 5 & American & exon 22 & c. $2851 T>G$ & p. Cys951Gly & Missense & $\begin{array}{l}\text { Had a chronic relapsing course, } \\
\text { responded to plasma infusion }\end{array}$ & [17] \\
\hline 6 & American & exon 13 & C. $1582 A>G$ & p. Arg528Gly & Missense & $\begin{array}{l}\text { Had a chronic relapsing course, } \\
\text { responded to plasma infusion }\end{array}$ & [17] \\
\hline 7 & American & exon 27 & c.3770dupT & $\begin{array}{l}\text { p. Leu- } \\
\text { 1258Valfs }\end{array}$ & Frameshift & $\begin{array}{l}\text { Had a chronic relapsing course, } \\
\text { responded to plasma infusion }\end{array}$ & [17] \\
\hline 8 & American & exon 10 & c. $1193 G>A$ & p. Arg398His & Missense & $\begin{array}{l}\text { Had a chronic relapsing course, } \\
\text { responded to plasma infusion }\end{array}$ & [17] \\
\hline 9 & American & exon 24 & c. $3070 \mathrm{~T}>\mathrm{G}$ & $\begin{array}{l}\text { p. Cys- } \\
\text { 1024Gly }\end{array}$ & Missense & $\begin{array}{l}\text { Had a chronic relapsing course, } \\
\text { responded to plasma infusion }\end{array}$ & [17] \\
\hline 10 & American & exon 3 & c. $304 C>T$ & p. Arg102Cys & Missense & $\begin{array}{l}\text { Microangiopathic haemolysis, } \\
\text { clinical response to plasma } \\
\text { infusion }\end{array}$ & [17] \\
\hline 11 & American & exon 6 & c. $587 C>\mathrm{T}$ & p. Thr196lle & Missense & $\begin{array}{l}\text { Microangiopathic haemolysis, } \\
\text { clinical response to plasma } \\
\text { infusion }\end{array}$ & [17] \\
\hline 12 & American & exon 19 & c.2376_2401del26 & $\begin{array}{l}\text { p. } \\
\text { Ala793Profs }\end{array}$ & Frameshift & $\begin{array}{l}\text { Microangiopathic haemolysis, } \\
\text { clinical response to plasma } \\
\text { infusion }\end{array}$ & [17] \\
\hline 13 & American & exon 26 & c. $3638 \mathrm{G}>\mathrm{A}$ & $\begin{array}{l}\text { p. Cys- } \\
\text { 1213Tyr }\end{array}$ & Missense & $\begin{array}{l}\text { Microangiopathic haemolysis, } \\
\text { clinical response to plasma } \\
\text { infusion }\end{array}$ & [17] \\
\hline 14 & American & - & c. $1584+5 G>A$ & - & Splice site & $\begin{array}{l}\text { Microangiopathic haemolysis, } \\
\text { clinical response to plasma } \\
\text { infusion }\end{array}$ & [17] \\
\hline \multirow[t]{2}{*}{15} & \multirow[t]{2}{*}{ Japanese } & intron 3 & c. $331-1 \mathrm{G}>\mathrm{A}$ & - & Splice site & \multirow{2}{*}{$\begin{array}{l}\text { Kidney failure and plastocyto- } \\
\text { penia }\end{array}$} & \multirow[t]{2}{*}{ [18] } \\
\hline & & exon 7 & c. $749 \mathrm{C}>\mathrm{T}$ & p. Ala250Val & Missense & & \\
\hline 16 & Japanese & intron 4 & $c .414+1 G>A$ & - & Splice site & $\begin{array}{l}\text { Plastocytopenia and hemolyti- } \\
\text { canemia (the patient's parents } \\
\text { are cousins) }\end{array}$ & [19] \\
\hline \multirow[t]{2}{*}{17} & \multirow[t]{2}{*}{ Japanese } & exon 7 & $c .803 G>C$ & p. Arg268Pro & Missense & \multirow{2}{*}{$\begin{array}{l}\text { Neonatal onset and frequent } \\
\text { relapses }\end{array}$} & \multirow[t]{2}{*}{ [20] } \\
\hline & & exon 12.13 & $\begin{array}{l}\text { c. } \\
{[1342 C>G ; 1523 G>A]}\end{array}$ & $\begin{array}{l}\text { p. Gln } 448 \mathrm{Glu} \\
\text { p. Cys508Tyr }\end{array}$ & $\begin{array}{l}\text { Missense } \\
\text { (haplotype) }\end{array}$ & & \\
\hline 18 & Japanese & exon 12 & c. $1345 C>T$ & p. Gln449Ter & Nonsense & $\begin{array}{l}\text { Neonatal onset and frequent } \\
\text { relapses }\end{array}$ & [20] \\
\hline 19 & American & exon 15 & c.1783_1784delTT & $\begin{array}{l}\text { p. Leu595G- } \\
\text { lyfs }\end{array}$ & Frameshift & $\begin{array}{l}\text { Plastocytopenia and microvas- } \\
\text { cular hemolysis }\end{array}$ & [21] \\
\hline 20 & Haitian & exon 16 & c. $1787 C>T$ & p. Ala596Val & Missense & $\begin{array}{l}\text { Neonatal hemolysis and } \\
\text { thrombocytopenia,chronic } \\
\text { hemolysis, proteinuria and } \\
\text { biliary stones }\end{array}$ & [22] \\
\hline
\end{tabular}


Table 1 (continued)

\begin{tabular}{|c|c|c|c|c|c|c|c|}
\hline Patient no & Ethnicity & $\begin{array}{l}\text { Site of } \\
\text { mutation } \\
\text { (exon no.) }\end{array}$ & Nucleotide change & $\begin{array}{l}\text { Amino acid } \\
\text { change }\end{array}$ & $\begin{array}{l}\text { Mutation } \\
\text { type }\end{array}$ & Clinical manifestation & References \\
\hline \multirow[t]{2}{*}{21} & \multirow[t]{2}{*}{ Chinese } & exon 6 & $c .581 \mathrm{G}>\mathrm{T}$ & p. Gly194Val & Missense & \multirow{2}{*}{$\begin{array}{l}\text { Hemolytic anemia, } \\
\text { thrombocytopenia,ecchymosis, } \\
\text { petechiae, decreased liver func- } \\
\text { tion, jaundice and fever }\end{array}$} & \multirow{2}{*}{$\begin{array}{l}\text { Department of } \\
\text { Hematology,303rd } \\
\text { Hospital of the } \\
\text { People's Libera- } \\
\text { tion Army (Aug 15, } \\
\text { 2018) }\end{array}$} \\
\hline & & exon 18 & c. $2209 \mathrm{~T}>\mathrm{C}$ & p. Cys737Arg & Missense & & \\
\hline 22 & Not available & exon 23 & c.2863dup & p. Trp955fs & Frameshift & Not available & $\begin{array}{l}\text { Mendelics (May 28, } \\
\text { 2019) }\end{array}$ \\
\hline 23 & Not available & - & c. $3044+1 G>A$ & - & Splice site & Not available & $\begin{array}{l}\text { GeneDx (Jan 29, } \\
\text { 2019) }\end{array}$ \\
\hline \multirow[t]{2}{*}{24} & Chinese & exon 11 & c.1335delC & $\begin{array}{l}\text { p. } \\
\text { Phe445Leuf- } \\
\text { sTer52 }\end{array}$ & Frameshift & \multirow{2}{*}{$\begin{array}{l}\text { Plastocytopenia, neurological } \\
\text { abnormalities and renal involve- } \\
\text { ment; Had a chronic relapsing } \\
\text { course, chronic hemolysis } \\
\text { responded to plasmainfusion }\end{array}$} & \multirow[t]{2}{*}{ This study } \\
\hline & & exon 18 & $c .2130 C>G$ & p. Cys710Trp & Missense & & \\
\hline
\end{tabular}

the genetic disease was available for assessment. She had no history of infectious diseases, no history of exposure to toxic substances or contaminated water, and no history of surgery, traumatic injury, blood transfusion, and drug or food allergies. Her vaccinations were performed as planned. At age of three, she was hospitalized for skin purpura, but no abnormality was observed in the bone marrow smear and she was diagnosed with "idiopathic thrombocytopenic purpura". Afterward, her platelet count decreased after each cold, and she was hospitalized intermittently. At age of eight, the patient was admitted to our department for "thrombocytopenia". Her blood urea concentration was $7.78 \mathrm{mmol} / \mathrm{L}$ and total bilirubin was $41.6 \mu \mathrm{mol} / \mathrm{L}$. After symptomatic treatment, her platelet count returned to a normal level, but the blood urea concentration was still elevated. The patient took prednisone for approximately 3 months. After discharge, she did not experience nausea, vomiting, swelling, reduced urine production, etc. At age of nine, the patient was hospitalized again in our department for "acute gastroenteritis". Her blood urea concentration was $8.86 \mathrm{mmol} / \mathrm{L}$ and total bilirubin was $65.2 \mu \mathrm{mol} / \mathrm{L}$. After symptomatic treatment, the symptoms disappeared and she was discharged from the hospital. The patient did not attend a follow-up visit. She had experienced coughs 10 days before this admission, but no fever. The symptoms were not improved by taking oral cough syrup. In the last 3 days, she exhibited weakness in the left limb, but no fever or convulsions.

Physical examination: At the time of this admission when the patient was 10 years old, her body temperature was $36.9^{\circ} \mathrm{C}$, her pulse rate was $88 / \mathrm{min}$, her breathing rate was $20 / \mathrm{min}$, her blood pressure was $141 / 81 \mathrm{mmHg}$, and her weight was $46 \mathrm{~kg}$. Her development was normal and consciousness was clear, but her gait was unstable. Slight pharyngeal hyperemia was observed, and bilateral tonsils were swollen in degree I. The breath in her lungs sounded thick, without dry or moist rales. No deformities of limbs and spine were observed. The muscle tension and volume of the limbs were normal. An ecchymosis was detected on the left knee and calf. The muscle strength of the right limb was normal. The muscle strength of the left upper limb was V-. The muscle strength of the left lower limb was normal. There was tenderness in the left gastrocnemius muscle, no sensory disturbances or pain, and no warmth disturbances. The rest of the respiratory, cardiovascular were normal.

Laboratory examination: The laboratory examination results of this admission showed anemia, thrombocytopenia, reticulocytosis, and hypertriglyceridemia. The results of her coagulation function analysis and renal function analysis also showed abnormalities. Her blood lactate dehydrogenase was elevated. Urinalysis revealed the presence of mild proteinuria. Meanwhile, her ADAMTS13 activity was lower than $2.5 \%$. Other hepatic analyses, cerebrospinal fluid analyses, myocardial enzymes, and immunoassay were normal (Table 2).

Cranial magnetic resonance imaging: The right side of the basal ganglia region-lateral ventricle showed a flaky and slightly longer signal on T1 and T2 images, a short signal on T2 images of the lesion center, slight hyperintensity in the center of pressure water sequence lesions surrounded by a ring of hyperintensity, hyperintensity in most of the DWI sequence lesions with flaky hypointensity inside the lesions, hypointensity in the lesions corresponding to the $\mathrm{ADC}$ figure, an obviously enhanced signal in the lesion center on the enhanced scan and no obvious abnormal signals and non-enhanced lesions in the brain parenchyma (Fig. 1). 
Table 2 Laboratory investigation findings of the patient

\begin{tabular}{|c|c|c|}
\hline Laboratory examination & Patient & Reference range \\
\hline \multicolumn{3}{|l|}{ Hematology and coagulation assays } \\
\hline White blood cell $\left(\times 10^{9} / \mathrm{L}\right)$ & 6.37 & $8-10$ \\
\hline Neutrophils (\%) & 70 & $50-70$ \\
\hline Lymphocytes (\%) & 24.9 & $20-40$ \\
\hline Hemoglobin (g/L) & 92 & $120-140$ \\
\hline Hematocrit (\%) & 28.2 & $35-45$ \\
\hline Reticulocyte (\%) & 3.09 & $0.5-1.5$ \\
\hline Platelets ( $\times 10^{9} / \mathrm{L}$ ) & 76 & $100-300$ \\
\hline Hypersensitive C-reactive protein (mg/L) & $<0.5$ & $<0.5$ \\
\hline Erythrocyte Sedimentation Rate (mm/h) & 18 & $0-20$ \\
\hline D-dimer (mg/L) & 0,58 & $<0.3$ \\
\hline Prothrombin activity (\%) & 59.5 & $75-100$ \\
\hline Prothrombin time (sec) & 14.1 & $12-14$ \\
\hline Blood triglyceride $(\mathrm{mmol} / \mathrm{L})$ & 6.01 & $<1.13$ \\
\hline \multicolumn{3}{|l|}{ Immunoassay } \\
\hline Immunoglobulin A (g/L) & 1.44 & $0.29-2.7$ \\
\hline Immunoglobulin E (U/L) & 21 & $<100$ \\
\hline Immunoglobulin G (g/L) & 8.61 & $7-16.5$ \\
\hline Immunoglobulin M (g/L) & 1 & $0.5-2.6$ \\
\hline Serum complement3 (g/L) & 0.99 & $0.9-1.8$ \\
\hline Serum complement4 (g/L) & 0.15 & $0.1-0.4$ \\
\hline Coombs test & Negative & Negative \\
\hline ADAMTS13 activity (\%) & $<2.5$ & $68-130$ \\
\hline \multicolumn{3}{|l|}{ Hepatic analysis } \\
\hline Total bilirubin ( $\mu \mathrm{mol} / \mathrm{L})$ & 14.4 & $3.4-17.1$ \\
\hline Direct bilirubin $(\mu \mathrm{mol} / \mathrm{L})$ & 3.8 & $0-6.8$ \\
\hline Alanine aminotransferase $(U / L)$ & 13 & $7-40$ \\
\hline Aspartate transaminase $(\mathrm{U} / \mathrm{L})$ & 26 & $13-35$ \\
\hline \multicolumn{3}{|l|}{ Renal analysis } \\
\hline Urea (mmol/L) & 14.41 & $2.6-8.8$ \\
\hline Creatinine ( $\mu \mathrm{mol} / \mathrm{L})$ & 184 & $41-81$ \\
\hline Uric acid ( $\mu \mathrm{mol} / \mathrm{L})$ & 596 & 119-327 \\
\hline \multicolumn{3}{|l|}{ Urinalysis } \\
\hline Qualitative protein analysis & + & Negative \\
\hline \multicolumn{3}{|l|}{ Cerebrospinal fluid analysis } \\
\hline Total cerebrospinal fluid protein (mg/L) & 245 & $200-400$ \\
\hline Cerebrospinal Fluid Chloride (mmol/L) & 130 & $117-127$ \\
\hline Cerebrospinal fluid glucose (mmol/L) & 3.22 & $2.8-4.5$ \\
\hline \multicolumn{3}{|l|}{ Myocardial enzymes } \\
\hline Creatine Kinase (U/L) & 162 & $25-170$ \\
\hline Lactate dehydrogenase (U/I) & 531 & $150-450$ \\
\hline Cardiac troponin I (pg/mL) & 30.49 & $<200$ \\
\hline
\end{tabular}

Bold represents the patient had an abnormality in this indicator

Renal needle biopsy: The images showed 1 renal cortex tissue, 11 glomeruli, 1 fibrocystic crescent, 1 cellular crescent, 1 region displaying focal segmental sclerosis, mild hyperplasia in the glomerular mesangium, the incomplete opening of the capillary loops, tubular atrophy, interstitial fibrosis, and low levels of inflammatory cell infiltration, vacuolar degeneration in renal tubule epithelial cells, calcification in certain tubule epithelial cells, a few swollen endothelial cells in the afferent vessel and the formation of a pink thrombus in the lumen of some small vessels. We considered that the girl may have suffered from nephropathy associated with the thrombotic microvasculature (Fig. 2). Immunofluorescence showed that only one glomerulus was found in the puncture specimen, C3 $(++), \mathrm{C} 1 \mathrm{q}( \pm), \operatorname{IgM}(++)$, IgA $( \pm)$, and were deposited in the segment-mesangial zone, $\operatorname{IgG}(-)$.

Electron microscopy images showed glomerular mesangial cell hyperplasia (1-3 cells/zone) with moderate nodular hyperplasia in the matrix, no obvious electron deposition, endothelial cell hyperplasia in part of the capillary (1-3 cells/vessel), cytoplasmic swelling, capillary basement membrane thickening (600-1000 nm), endothelial loosening, extensive podocyte fusion, edema in some renal tubular epithelial cells, interstitial fibroproliferation, two small arteries with necrotic endothelial cells, and the deposition of particles. The glomeruli showed moderate mesangial hyperplasia and basement membrane thickening and loosening, as well as hyperplasia and edema in endothelial cells (Fig. 3, Additional file 1: Fig. S1).

Gene sequencing: The patient's ADAMTS13 gene contains compound heterozygous nucleotide variations: c.1335delC (p. Phe445LeufsTer52) is a frameshift variation inherited from her father. c. $2130 \mathrm{C}>\mathrm{G}$ (p. Cys710Trp) is a missense variation inherited from her mother (Fig. 4). The frameshift variation changes the amino acid synthesis starting from phenylalanine 445 and ends at the 52nd amino acid after the change, resulting in a significant change in the structure of the protein. The missense variation causes amino acid 710 to be changed from Cysteine to Tryptophan (Fig. 5). We submitted these two variants to ClinVar, the submission numbers are SUB10260642 and SUB10296888 respectively.

Variant's pathogenicity: We qualified the functional impact of the reported variants by using in-silico algorithms. The pathogenicity of p. Cys710Trp was quantified by using Polymorphism Phenotyping v2 (PolyPhen2) and Protein Variation Effect Analyzer (PROVEAN) algorithms; since frameshift mutations are not applicable to the " PolyPhen2" and " PROVEAN " algorithms, we used "AutoPVS1" algorithm to quantify the pathogenicity of p. Phe445Leufs" 52 .

"PolyPhen2" algorithm shows that the pathogenicity of p. Cys710Trp mutation is predicted to be "PROBABLY DAMAGING" with a score of 1.000 (sensitivity: 0.00; specificity: 1.00). "PROVEAN" algorithm shows 


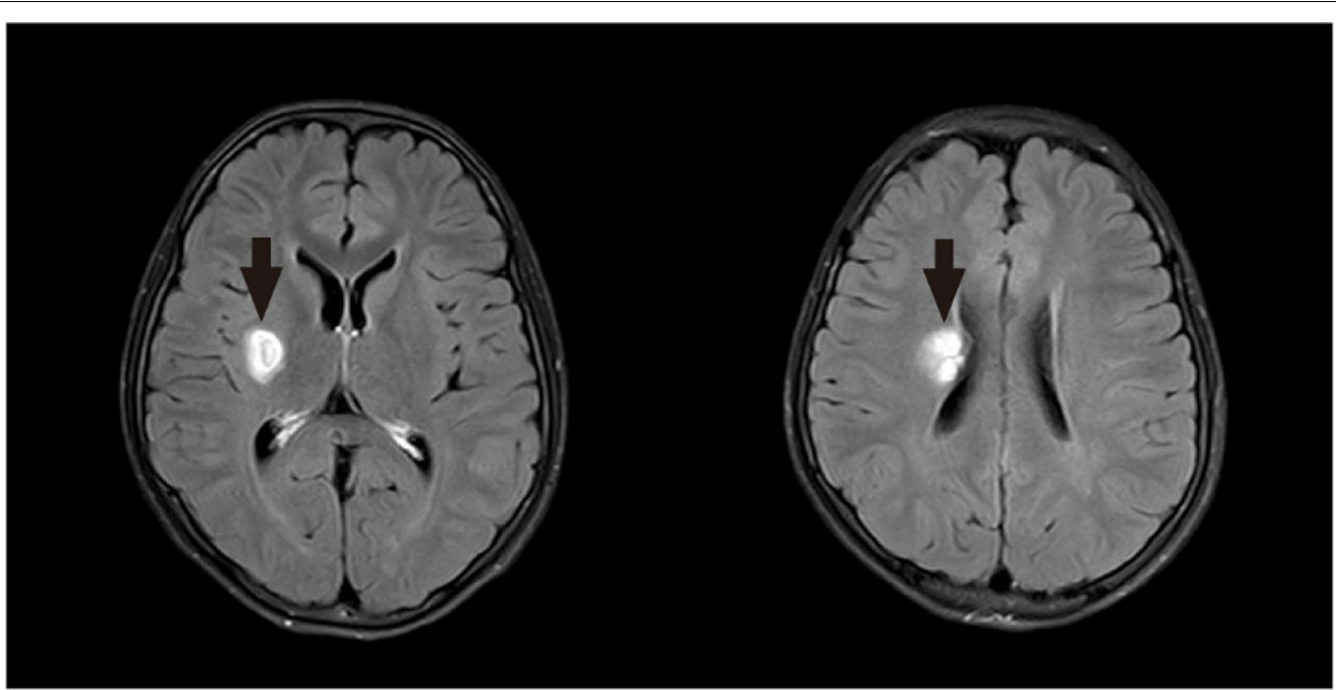

Fig. 1 Cranial magnetic resonance images obtained from the patient. The black arrow shows the right side of the basal ganglia region-lateral ventricle lesion

A

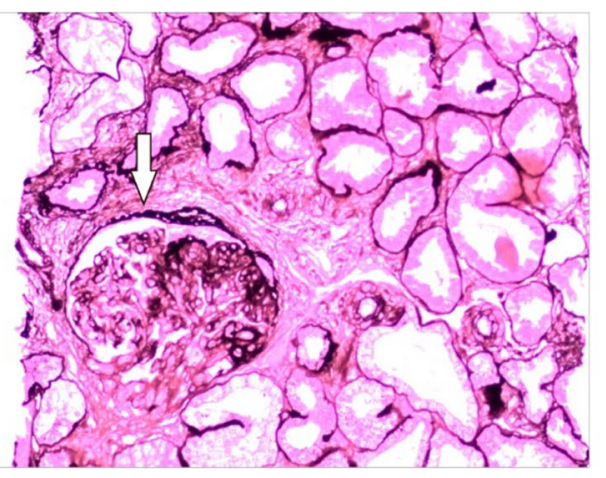

B

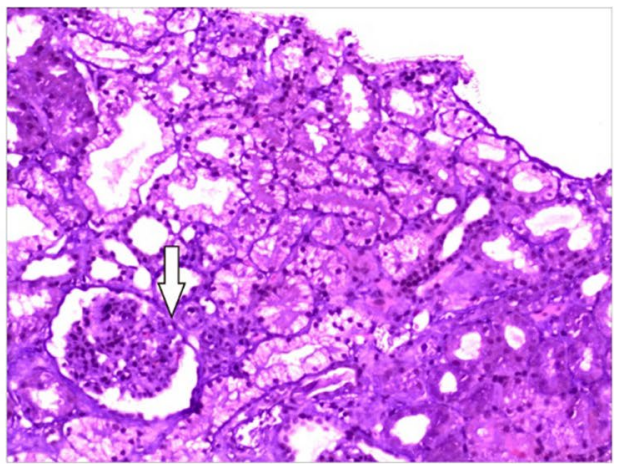

Fig. 2 Images of the patient's renal needle biopsy. A The white arrow shows a crescent forming in the glomerulus (PASM). B The white arrow shows glomerular capillaries exhibiting glassy transformation and sclerosis (HE)

A

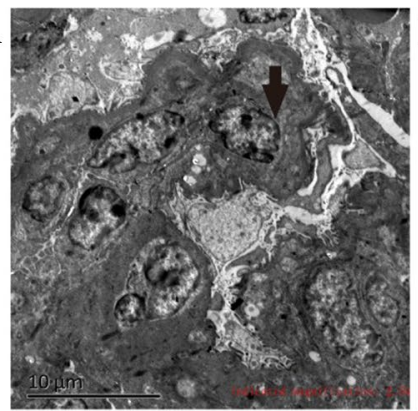

B

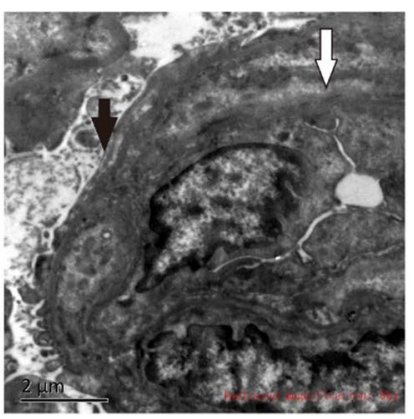

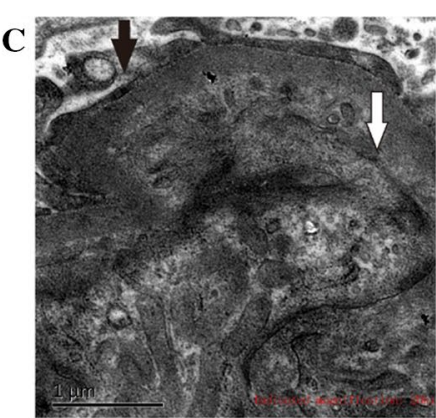

Fig. 3 Electron microscopy images of the patient's renal needle biopsy. A The black arrow shows renal tubular epithelial cell edema and interstitial fibroproliferation. B The black arrow shows extensive podocyte fusion, and the white arrow shows thickening of the capillary basement membrane and endothelial loosening. C The black arrow shows the disappearance of epithelial podocytes from the visceral layer, and the white arrow shows necrotic endothelial cells and the deposition of particles 


\section{c. 1335 delC}

A

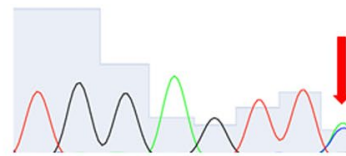

c. $1335 \mathrm{delC}$

C

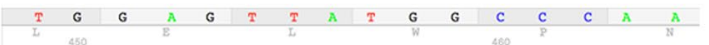

Father

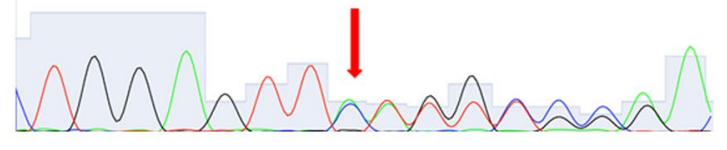

c. 1335 delC

$\mathbf{E}$

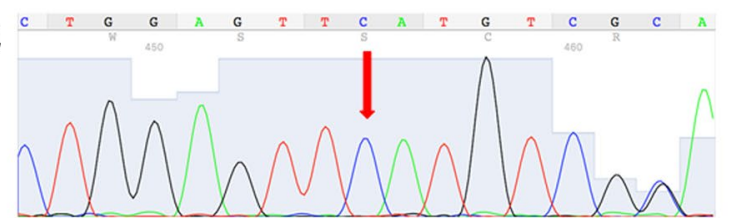

c. $2130 \mathrm{C}>\mathrm{G}$

B

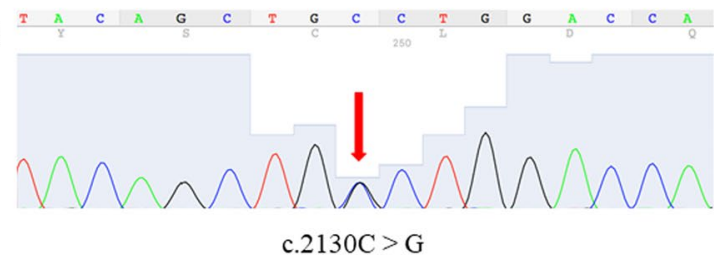

D

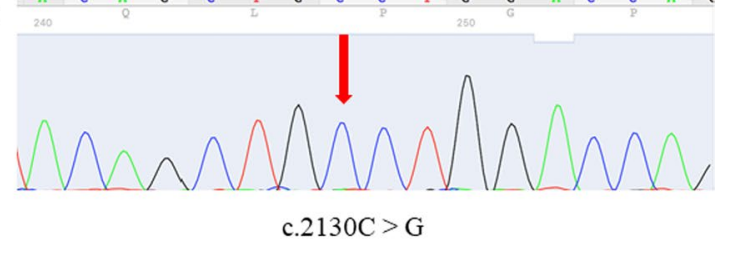

$\mathbf{F}$

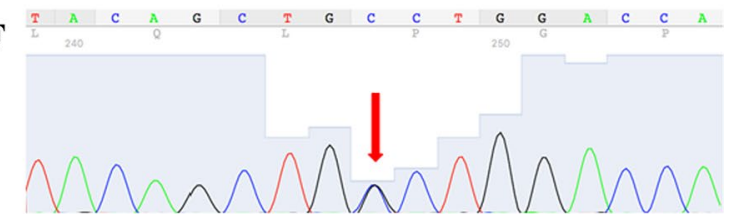

Fig. 4 Sequences of ADAMTS13 gene. A The proband carried the heterozygous mutation c.1335delC (p. Phe445LeufsTer52). B The proband carried the heterozygous mutation c.2130C > G (p. Cys710Trp). C The father of the proband carried the heterozygous mutation c.1335delC (p. Phe445LeufsTer52). D The father of the proband did not carry the mutation in site c.2130. E The mother of the proband did not carry the mutation in site c.1335. F The mother of the proband carried the heterozygous mutation c.2130C > G (p. Cys710Trp)

A

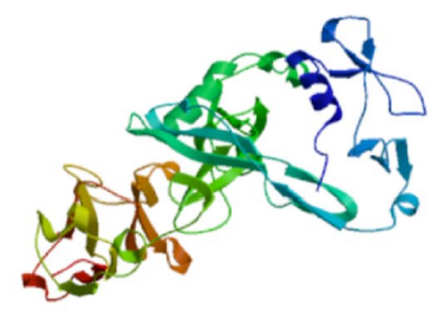

B

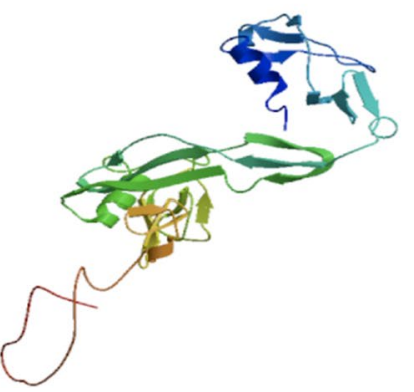

C

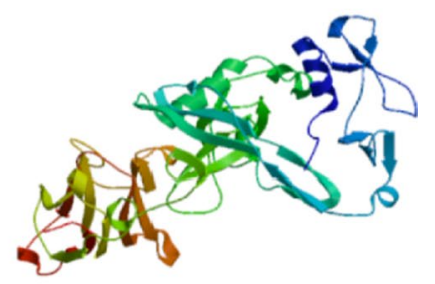

Fig. 5 Structures of the protein encoded by the ADAMTS13 gene. A Structure of the wild type ADAMTS13 protein. B Structure of the ADAMTS13 protein with the mutation in c.1335. C Structure of the ADAMTS13 protein with the mutation in c.2130

that the pathogenicity of $\mathrm{p}$. Cys710Trp mutation is predicted to be "Deleterious" with a PROVEAN score of -9.836 (cutoff $=-2.5$ ). AutoPVS1 shows that the pathogenicity of p. Phe445Leufs" 52 is "PSV1', which means very strong evidence of pathogenicity.

The girl was diagnosed with hereditary TTP, which was treated with oral nifedipine, dipyridamole, and coated aldehyde oxystarch capsules. She was discharged from the hospital after two weeks and continued to take the medications at home. In January 2018, the patient was readmitted to PICU in our hospital for the same disease. Her condition improved after treatment with plasma exchange, after which she was discharged.

\section{Discussion and conclusions}

In this study, we analyzed the activity of patients' ADAMTS13 and performed genetic sequencing to diagnose the patient with USS. To the best of our knowledge, our report is the first report of mutations in these two pathogenic variants and is the first review that combines all the pathogenic mutations with available details.

Thrombotic thrombocytopenic purpura (TTP), which was first reported by Moschcowitz in 1924, is a rare kind 
of thrombotic microangiopathy (TMA). The incidence of TTP is $1-2 / 1,000,000$. The male-to-female ratio is $2: 3$ [1]. Its main clinical manifestations include hemolytic anemia, severe thrombocytopenia, neurological abnormalities, fever, and renal involvement, which are called the "Penta sign", and the first three manifestations are called the "Triad sign". The central nervous system and kidney are the two most common organs or systems affected by TTP [2]. TTP is characterized by a rapid onset, with early mortality of up to $90 \%$, and some patients eventually progress to end-stage renal disease (ESRD) [3].

Based on our literature review of 29 ADAMTS13 pathogenic mutations detected in 24 patients, we found that missense mutations (55\%) are the most common type of mutation, followed by frameshift mutations (28\%). Exons contained more mutations than introns. 11 patients (45.8\%) showed the course of chronic relapsing TTP. 13 patients (54.2\%) responded to plasma infusion. Nine patients (37.5\%) had a history of hemolysis. (Table 1). Similar to half of the reported case, our patient also showed a chronic onset course and response to plasma exchange. Although neurological symptoms are a major symptom of TTP, it is rare in case reports. However, our patient has obvious neurological symptoms. Another outstanding feature is that there was no manifestation of fever or severe hemolytic anemia during this hospitalization, although her total bilirubin did increase significantly during her three hospitalizations between 8 and 9 years old. And after that she developed abnormal renal function. Jaundice is a common feature among the pediatric cases of USS, but the signs and symptoms of USS are not static. The Penta sign of USS is present in only $10 \%$ of patients [4]. This time she was admitted to the hospital due to cough and left limb weakness. Her hemolytic symptoms were chronic and did not occur acutely recently. This may be the reason why the patient had no jaundice with normal liver function this time.

The main pathogenic mechanism of TTP is related to the lack of the activity of the vWF-cleaving protease ADAMTS13, the abnormal release of vWF from vascular endothelial cells, and abnormal platelet activation, etc. ADAMTS13 contains disintegrin and metalloprotease domains with thrombospondins1 repeats and is the 13th member of the ADAMTS family. The gene is located on chromosome 9q34 and comprises 29 exons. ADAMTS13 was discovered in 1996, and its deficiency is unique to TTP and is not detected in other types of microvascular diseases, such as hemolysis and thrombosis. ADAMTS13 is synthesized by the liver and its main function is to cleave vWF from the vascular endothelial cell surface, in the blood circulation, and at vascular injury sites [5]. vWF is a type of macromolecular adhesive glycoprotein that is present as a polymer with a molecular weight of
500-20,000 in plasma and is an essential component of the normal hemostasis process [6]. Under physiological conditions, vWF is hydrolyzed by proteolytic enzymes to different degrees, among which ADAMTS13 is an important hydrolytic enzyme. ADAMTS13 gene mutations or related IgG antibody generation result in a lack of activity of ADAMTS13 enzymes, the reduced clearance of vWF from vascular endothelial cells, the generation of the unusually large von-Willebrand-Factor (ULvWF), vWF and platelet aggregation into microvascular thrombosis, platelet consumption, microvascular thrombosis, and microangiopathy hemolytic anemia, causing tissue thromboembolism, failure and eventual death [7]. According to recent studies, the reduced activity of tissue plasminogen activator (tPA) is also associated with the occurrence of TTP. tPA converts fibrinogen into fibrinase, which degrades the vWF polymer in various sites and also cleaves adhesion molecules between the walls of blood vessels and the platelet. Therefore, the reduction of the activity of tPA results in similar effects to decreased ADAMTS13 activity, resulting in the formation of microvascular thrombosis and producing a series of pathological changes, suggesting that a reduction in the tPA activity is one of the most likely causes of idiopathic TTP [8]. Unfortunately, a tPA test was not performed on this patient.

The frameshift mutation c.1335delC is located in the cysteine-rich domain, and all other TSP1 repeat domains after the appearance of the stop codon disappear. This may be related to the early onset of the disease and the repeated chronic course phenotype. The missense mutation c. $2130 \mathrm{C}>\mathrm{G}$ is located between the spacer domain and the TSP1 domain, which may indicate a lighter TTP phenotype [9]. We speculate that in this compound heterozygous mutation, the frameshift mutation is the main cause of severe symptoms in patients. However, more information about the relationship between the genotype and phenotype of these two mutations requires the support of in vitro experiments.

TTP is classified into hereditary and acquired forms, the latter of which is classified as idiopathic and secondary, according to the presence or absence of the primary disease. Hereditary TTP, also known as Upshaw-Schulman syndrome (USS), is a rare autosomal recessive hereditary disease caused by a decrease in or lack of enzyme activity due to a homozygous or heterozygous mutation of the ADAMTS13 gene [10]. USS has manifested as two phenotypes: an early-onset phenotype that has been observed in newborns and the delayed-onset phenotype that usually does not produce symptoms in childhood, whereas the first symptoms occur after puberty or in adulthood [11]. The patient in this case study experienced symptoms at the age of 2 and thus was diagnosed 
with early-onset USS. Idiopathic TTP is the main clinical type of acquired TTP. Autoantibodies or inhibitors of ADAMTS13 in patients, mainly the IgG type, results in a decrease in or lack of ADAMTS13 enzyme activity, which usually occurs in patients with genetic risk factors, more than $95 \%$ of whom are adults [12]. Secondary TTP is caused by an infection, drugs, tumors, autoimmune diseases, hematopoietic stem cell transplantation, and other factors; this type of TTP is characterized by complicated pathogenesis and poor prognosis. Regardless of whether the patient is diagnosed with hereditary or acquired TTP, plasma levels of ADAMTS13 enzymes must be detected before the administration of plasma treatment. For patients with enzyme activity $<10 \%$, ADAMTS13 antibodies should be detected. If the antibody test is negative, sequencing should be performed to identify mutations in exons of the ADAMTS13 gene for the differential diagnosis of hereditary TTP in the patient [13]. If the antibody test is positive, the patient should be diagnosed with secondary TTP. The detection of ADAMTS13 activity and antibodies is not merely conducive to a differential diagnosis but also the application of more targeted treatments, predictions of relapse, and the determination of long-term prognoses of patients with TTP [5]. In this case, the relevant antibodies were not detected.

Currently, the diagnosis of TTP requires the presence of the following features: the clinical manifestations of TTP; typical changes in blood cell counts and biochemical parameters; a significant decrease in the plasma level of ADAMTS13 activity, as the ADAMTS13 inhibitor is often detected in patients with idiopathic TTP, but cannot be detected in some patients and patients with the hemolytic uremic syndrome (HUS), disseminated intravascular coagulation (DIC), hemolysis, elevated liver enzymes, and thrombocytopenia syndrome (HELLP), but not Evans syndrome and eclampsia. The disease is dangerous and has a high fatality rate. Aggressive treatment should be initiated as soon as possible after the patient receives a definitive diagnosis or is highly suspected of having a slight or severe case of the disease. Plasma replacement therapy is preferred, followed by fresh (frozen) plasma infusion and medication. In highly suspected and confirmed cases, platelet transfusion should be cautiously administered and should be considered for use only when severe life-threatening bleeding occurs. The main treatment for acute onset hereditary TTP is plasma exchange/plasma infusion. The main treatment for secondary TTP is plasma exchange, and if necessary, it can be combined with immunosuppressive agents [14]. Approximately $30-40 \%$ of patients with TTP may experience a relapse within 10 years of complete remission. In this situation, plasma exchange therapy should be resumed as soon as possible [15]. The patient in our case study exhibited a stable condition after plasma exchange and was discharged from the hospital.

In this case report, we described a 10-year-old girl with two compound heterozygous ADAMTS13 variants. The patient was diagnosed with hereditary TTP. She showed neurological symptoms without serious coagulation abnormalities. The relationship between genotype and phenotype in these two mutations requires further in vitro investigation.

\begin{abstract}
Abbreviations
TTP: thrombotic thrombocytopenic purpura; USS: Upshaw-Schulman syndrome; TMA: thrombotic microangiopathy; ESRD: end-stage renal disease; VWF: Von Willebrand factor; ULVWF: unusually large von-Willebrand-Factor: tPA: tissue plasminogen activator; HUS: hemolytic uremic syndrome; DIC: disseminated intravascular coagulation.
\end{abstract}

\section{Supplementary Information}

The online version contains supplementary material available at https://doi. org/10.1186/s12920-021-01099-3.

Additional file 1. Electron microscopy images of the patient's renal needle biopsy.

Acknowledgements

We thank American Journal Experts for its language editing service.

\section{Authors' contributions}

$\mathrm{PL}$ collected the data and wrote the manuscript; IJ and QX analyzed the data and revised the manuscript; and ZY diagnosed the disease, designed the experiments and revised the manuscript. All the authors have accepted responsibility for the entire content of this submitted manuscript and approved submission. All authors read and approved the final manuscript.

\section{Funding}

This work was supported by the New Xiangya Talent Project of the Third Xiangya Hospital of the Central South University (Grant No. JY20150312). The funding body played no role in the design of the study and collection, analysis, and interpretation of data and in writing the manuscript.

\section{Availability of data and materials}

The datasets generated and analyzed during the current study are available in the ClinVar archive, under the Accession Number SCV001815641 and SCV001810646. The below listed databases are used for data analysis. ClinVar: https://www.ncbi.nlm.nih.gov/clinvar/; PolyPhen2: http://genetics.bwh.harva rd.edu/pph2/; PROVEAN: http://provean.jcvi.org/; AutoPVS1: http://autopvs1. genetics.bgi.com/.

\section{Declarations}

Ethics approval and consent of participate

This study has been performed in accordance with the Declaration of Helsinki and has been approved by the ethic committee of Third Xiangya Hospital, Central South University. Written informed consent to participate was obtained from patient's parents.

\section{Consent to publish}

We obtained informed written consent from the patient's parents for the publication of this case report.

\section{Competing interests}

The authors declare that they have no competing interests. 
Received: 18 April 2021 Accepted: 12 October 2021

Published online: 26 October 2021

\section{References}

1. Trachtman H. HUS and TTP in CHILDREN. Pediatr Clin N Am. 2013;60(6):1513-26

2. Krogh AS, Waage A, Quist-Paulsen P. Congenital thrombotic thrombocytopenic purpura. Tidsskr Nor Laegeforen. 2016;136(17):1452-7.

3. Masias C, Cataland SR. The role of ADAMTS13 testing in the diagnosis and management of thrombotic microangiopathies and thrombosis. Blood. 2018;132(9):903-10.

4. Joly BS, Coppo P, Veyradier A. Thrombotic thrombocytopenic purpura. Blood. 2017;129(21):2836-46.

5. Zheng XL. ADAMTS13 and von Willebrand factor in thrombotic thrombocytopenic purpura. Annu Rev Med. 2015;66:211-25.

6. Crawley JT, de Groot R, Xiang Y, Luken BM, Lane DA. Unraveling the scissile bond: how ADAMTS13 recognizes and cleaves von Willebrand factor. Blood. 2011:118(12):3212-21.

7. Naito C, Ogawa Y, Yanagisawa K, Ishizaki T, Mihara M, Handa H, et al. Acquired thrombotic thrombocytopenic purpura after vascular prosthesis implantation for impending rupture of an abdominal aortic aneurysm. Rinsho Ketsueki. 2016:57(3):364-8.

8. Hoirisch-Clapauch S, Nardi AE. A role for tissue plasminogen activator in thrombotic thrombocytopenic purpura. Med Hypotheses. 2014;83(6):747-50.

9. Camilleri RS, Scully M, Thomas M, Mackie IJ, Liesner R, Chen WJ, et al. A phenotype-genotype correlation of ADAMTS13 mutations in congenital thrombotic thrombocytopenic purpura patients treated in the United Kingdom. J Thromb Haemost. 2012;10(9):1792-801.

10. George JN, Nester CM. Syndromes of thrombotic microangiopathy. N Engl J Med. 2014:371(7):654-66.

11. Yagi H, Yamaguchi N, Shida Y, Sugimoto M, Tubaki $K$, Fujimura Y, et al. Highly elevated plasma level of von Willebrand factor accelerates the formation of platelet thrombus under high shear stress in plasma with deficient ADAMTS13 activity. Thromb Res. 2017;159:91-5.

12. Coppo P, Busson M, Veyradier A, Wynckel A, Poullin P, Azoulay E, et al. HLA-DRB1*11: a strong risk factor for acquired severe ADAMTS13 deficiency-related idiopathic thrombotic thrombocytopenic purpura in Caucasians. J Thromb Haemost. 2010;8(4):856-9.
13. Loirat C, Coppo P, Veyradier A. Thrombotic thrombocytopenic purpura in children. Curr Opin Pediatr. 2013;25(2):216-24

14. Thrombosis and Hemostasis Group, Hematology Society, Chinese Medical Association. Consensus of Chinese experts on diagnosis and treatment of thrombotic thrombocytopenic purpura (version 2012). Zhonghua Xue Ye Xue Za Zhi. 2012;33(11):983-4

15. Kremer Hovinga JA, Vesely SK, Terrell DR, Lammle B, George JN. Survival and relapse in patients with thrombotic thrombocytopenic purpura. Blood. 2010;115(8):1500-11.

16. Peyvandi F, Ferrari S, Lavoretano S, Canciani MT, Mannucci PM. von Willebrand factor cleaving protease (ADAMTS-13) and ADAMTS-13 neutralizing autoantibodies in 100 patients with thrombotic thrombocytopenic purpura. Br J Haematol. 2004;127(4):433-9.

17. Levy GG, Nichols WC, Lian EC, Foroud T, McClintick JN, McGee BM, et al. Mutations in a member of the ADAMTS gene family cause thrombotic thrombocytopenic purpura. Nature. 2001;413(6855):488-94.

18. Uchida T, Wada H, Mizutani M, Iwashita M, Ishihara H, Shibano T, et al. Identification of novel mutations in ADAMTS13 in an adult patient with congenital thrombotic thrombocytopenic purpura. Blood. 2004;104(7):2081-3.

19. Matsumoto M, Kokame K, Soejima K, Miura M, Hayashi S, Fujii Y, et al. Molecular characterization of ADAMTS13 gene mutations in Japanese patients with Upshaw-Schulman syndrome. Blood. 2004;103(4):1305-10.

20. Kokame K, Matsumoto M, Soejima K, Yagi H, Ishizashi H, Funato M, et al. Mutations and common polymorphisms in ADAMTS13 gene responsible for von Willebrand factor-cleaving protease activity. Proc Natl Acad Sci U S A. 2002:99(18):11902-7.

21. Savasan S, Lee SK, Ginsburg D, Tsai HM. ADAMTS13 gene mutation in congenital thrombotic thrombocytopenic purpura with previously reported normal WWF cleaving protease activity. Blood. 2003;101(11):4449-51.

22. Veyradier A, Lavergne JM, Ribba AS, Obert B, Loirat C, Meyer D, et al. Ten candidate ADAMTS13 mutations in six French families with congenital thrombotic thrombocytopenic purpura (Upshaw-Schulman syndrome). J Thromb Haemost. 2004;2(3):424-9.

\section{Publisher's Note}

Springer Nature remains neutral with regard to jurisdictional claims in published maps and institutional affiliations.
Ready to submit your research? Choose BMC and benefit from:

- fast, convenient online submission

- thorough peer review by experienced researchers in your field

- rapid publication on acceptance

- support for research data, including large and complex data types

- gold Open Access which fosters wider collaboration and increased citations

- maximum visibility for your research: over 100M website views per year

At BMC, research is always in progress.

Learn more biomedcentral.com/submissions 